Spending

OF MIDDLE-INCOME FAMILIES 
Issued under the Auspices of the

Heller Committee for Research in Social Economics

University of California 
Spending

OF MIDDLE-INCOME FAMILIES

Incomes and Expenditures of Salaried Workers in the San Francisco Bay Area in 1950

\section{EMILY H. HUNTINGTON}

With the assistance of

Mary H. Hawes and Esther Oswalt

1957

University of California Press - Berkeley - Los Angeles 
University of California Press

Berkeley and Los Angeles, California

Cambridge University Press

London, England

(c) 1957

By The Regents of the University of California

Library of Congress Catalog Card Number: 57-7592

Manufactured in the United States of America 
THE

HELLER COMMITTEE

For Research in Social Economics of the University of California 1956

Emily H. Huntington, Chairman

Barbara N. Armstrong

Sidney S. Hoos

Harvey Leibenstein

Davis McEntire

Ruth Okey 



\section{PREFACE}

This study, published under the auspices of the Heller Committee for Research in Social Economics, is the most recent of a series of Heller Committee studies of incomes and expenditures. Its special contribution is that it provides detailed evidence as to the patterns of consumption of salaried workers in occupations above routine clerical workers but below the executive class. Many other income and expenditure studies have been made, but none have segregated this socioeconomic group for special study.

As is always true of statistical studies, the results are based on the work of many people. Special gratitude is due two persons on the Heller Committee staff-Mary H. Hawes and Esther Oswalt, who were responsible not only for the preparation of the original drafts of many sections, but were largely responsible for some of the chapters which appear in the final manuscript. Miss Hawes and Mrs. Oswalt also contributed suggestions as to the methods of analysis to be used. I should like to thank also Vera Hopkins, whose careful supervision of the field work resulted in a high degree of accuracy of the raw materials. Thanks are also expressed to Lucille Bonsack, secretary of the Heller Committee for the laborious task of typing the manuscript, and to Maria Draeger, who worked long and carefully in checking computations. Others who contributed are too numerous to name, but appreciation is due those who assisted in securing the names of firms to be visited, to the firms who coöperated, to the field workers whose long hours of careful work made the raw materials available, and finally, of course, to the 159 families who gave the necessary detailed information about their incomes and expenditures.

As stated in chapter 1, Professor Jerzy Neyman, head of the Department of Statistics, University of California, Berkeley, suggested a method which tested the extent to which the sample of 159 families may be representative of other families. I am grateful to Professor Neyman for his advice as to 
the techniques and procedures to be used and also to members of his staff who made the laborious calculations which were required.

This study was financed in the main by the regular annual donation from Mrs. E. S. Heller and by funds granted by the University to the Heller Committee. Some additional funds were made available by the Bureau of Business and Economic Research and by the Institute of Social Sciences of the University of California.

The question always arises whether to place a summary chapter at the beginning or end of such a study as this. Since the body of this manuscript includes details in which some readers may not be interested, the decision was made to follow the chapter on "Scope and Method" with the summary. The reader who prefers to examine the detail first may wish at once to read through the later chapters.

Emily H. Huntington 